\title{
Urine concentration ability is reduced to the same degree in adult dominant polycystic kidney disease compared with other chronic kidney diseases in the same CKD-stage and lower THAN in healthy control subjects - a CASE control study
}

\author{
M. H. Malmberg * (D, F. H. Mose, E. B. Pedersen and J. N. Bech
}

\begin{abstract}
Background: Concentration of the urine is primarily regulated via vasopressin dependent aquaporin-2 water channels in the apical membrane of kidney principal cells. It is unclear whether urine concentration ability in ADPKD differs from other patients with similar degree of impaired renal function (non-ADPKD patients). The purpose of this case control study was to measure urine concentration ability in ADPKD patients compared to non-ADPKD patients and healthy controls.

Methods: A seventeen hour long water deprivation test was carried out in 17 ADPKD patients (CKD I-IV), 16 non-ADPKD patients (CKD I-IV), and 18 healthy controls. Urine was collected in 4 consecutive periods during water deprivation $(12 \mathrm{~h}, 1 \mathrm{~h}$, $2 \mathrm{~h}$ and $2 \mathrm{~h}$, respectively) and analyzed for osmolality ( $\mathrm{U}-\mathrm{Osm})$, output (UO), fractional excretion of sodium ( $\mathrm{FE}_{\mathrm{Na}}$ ), aquaporin2 (u-AQP2) and ENaC (u-ENaC). Blood samples were drawn trice (after 13-, 15-, and $17 \mathrm{~h}$ after water deprivation) for analyses of osmolality ( $p$-Osm), vasopressin ( $p$-AVP), and aldosterone ( $p$-Aldo).

Results: U-Osm was significantly lower and $\mathrm{FE}_{\mathrm{Na}}$ significantly higher in both ADPKD patients and non-ADPKD patients compared to healthy controls during the last three periods of water deprivation. During the same periods, $\mathrm{UO}$ was higher and secretion rates of $\mathrm{U}-\mathrm{AQP} 2$ and $\mathrm{u}-\mathrm{ENaC}$ were lower and at the same level in the two groups of patients compared to controls. P-AVP and p-Osm did not differ significantly between the three groups. P-Aldo was higher in both groups of patients than in controls.
\end{abstract}

Conclusions: Urine concentration ability was reduced to the same extent in patients with ADPKD and other chronic kidney diseases with the same level of renal function compared to healthy controls. The lower urine excretion of AQP2 and ENaC suggests that the underlying mechanism may be a reduced tubular response to vasopressin and aldosterone.

Trial registration: Current Controlled Trial NCT04363554, date of registration: 20.08.2017.

Keywords: Aldosterone, Angiotensin II, aquaporin2, Blood pressure, Chronic kidney disease, Epithelial sodium channel, GFR, Osmolality, Polycystic kidney disease, Renin, Sodium, Vasopressin

\footnotetext{
* Correspondence: mymalmbe@rm.dk

University Clinic in Nephrology and Hypertension, Regional Hospital West

Jutland and University of Aarhus, Holsstebro, Denmark
}

\section{$\triangle B M C$}

(c) The Author(s). 2020 Open Access This article is licensed under a Creative Commons Attribution 4.0 International License, which permits use, sharing, adaptation, distribution and reproduction in any medium or format, as long as you give appropriate credit to the original author(s) and the source, provide a link to the Creative Commons licence, and indicate if changes were made. The images or other third party material in this article are included in the article's Creative Commons licence, unless indicated otherwise in a credit line to the material. If material is not included in the article's Creative Commons licence and your intended use is not permitted by statutory regulation or exceeds the permitted use, you will need to obtain permission directly from the copyright holder. To view a copy of this licence, visit http://creativecommons.org/licenses/by/4.0/ The Creative Commons Public Domain Dedication waiver (http://creativecommons.org/publicdomain/zero/1.0/) applies to the data made available in this article, unless otherwise stated in a credit line to the data. 


\section{Background}

Urine volume is primarily regulated by vasopressin and aquaporin-2 water channels in the apical membrane of principal cells in the kidney [1]. The renin-angiotensinaldosterone system, the natriuretic peptide system and the sympathetic adrenergic nervous system also play a role in the opening degree of the AQP2 channels and therefore affect urine concentration [2-7]. The ability to concentrate urine can be measured by a water deprivation test. Generally, urine concentration is reduced in kidney diseases, but the underlying mechanisms and the severity may deviate in different kidney disease, although the degree of renal impairment is the same $[8,9]$.

Autosomal dominant polycystic kidney disease (ADPK D) is a common genetic disease, which is characterized by the formation of cysts in the kidneys, leading to renal impairment [10]. Previous studies indicated that vasopressin is a significant factor in the pathogenesis and progression of the disease by stimulating the growth of kidney cysts [11-14]. Meijer et al. showed that in an early stage of ADPKD, patients had an increased urine output and decreased urine osmolality compared to healthy controls [15]. Zittema et al. suggested that ADPKD patients had a decreased urine concentration ability, higher plasma osmolality, and higher plasma vasopressin compared to healthy individuals [16]. In a previous study, ADPKD patients had an impaired urine concentration ability compared to patients with IgA-nephropathy, and it was suggested that urine concentration ability was impaired to a larger extent during progressive renal disease in ADPKD than in other chronic kidney diseases [17]. However, it is unclear whether urine concentration ability in ADPKD differs from patients with impaired renal function due to other causes (non-ADPKD patients).

The purpose of the present case-control study was to perform a urine concentration test in patients with ADPKD (Group1), in patients with chronic kidney diseases without ADPKD (Group 2) and in healthy control subjects (Group 3). We measured:1) Urine osmolality (u-Osm), urine output (UO), free water clearance $\left(\mathrm{C}_{\mathrm{H} 20}\right)$, fractional excretion of sodium $\left(\mathrm{FE}_{\mathrm{Na}}\right)$.

2) Urine excretion of aquaporin 2 water channels (u$\mathrm{AQP} 2$ ) and urine excretion of a fraction of the epithelial sodium channels (u-ENaC), 3) Plasma concentrations of vasopressin (p-AVP), renin (PRC), angiotensin II (pAngII) and aldosterone (p-Aldo), and plasma osmolality (p-Osm), 4) Blood pressure (BP), augmentation index (AIx) and Pulse wave velocity (PWV).

We hypothesized that ADPKD patients have decreased urinary concentration ability compared to non-ADPKD patients with chronic kidney disease, as well as compared to healthy controls. We also hypothesized that a difference in urinary concentration ability between ADPKD and non-ADPKD and the control group may be explained by a change in the renal tubular response and/ or changes in vasoactive hormones.

\section{Methods \\ Study design}

The design was as a case-control study with three groups. Group 1 comprised patients with ADPKD, Group 2 comprised patients with chronic kidney diseases other than ADPKD, and Group 3 comprised healthy control subjects. Each subject was examined once.

\section{Recruitment}

Participants was recruited in the period between September 2017 and November 2018. In Groups 1 and 2, patients were recruited from the Outpatient Clinic of Nephrology in University Clinic in Nephrology and Hypertension, Department of Medicine at Holstebro Hospital, Denmark. Healthy controls in Group 3 were recruited by advertising in the local newspaper. All three groups were matched regarding age and gender. The two patient groups were matched regarding GFR.

\section{Subjects \\ Inclusion criteria}

Group 1 Patients with ADPKD. Age 18 years or older. Men and unfertile women or fertile women using safe contraception throughout the trial period (safe contraception was defined as: sterilization, birth control pills, spiral, subdermal implantation, hormonal vaginal ring, transdermal patch, depot injection of progestogen or sexual abstinence). Kidney function corresponding to chronic kidney disease (CKD) stages I-IV (eGFR > 15 $\mathrm{mL} / \mathrm{min} / 1.73 \mathrm{~m} 2$ ). Patients were included if a genetic test revealed PKD1 and PKD2 mutations. If a genetic test was not performed, patients were included in accordance with the classic Ravine criteria using ultrasonographic findings. Thus, ADPKD patients were diagnosed by genetic testing for PKD1 and PKD2 mutations, or presence of one of the following ultra- sonographic findings in accordance to the classic Ravine criteria. Patients with a negative family history of ADPKD with more than 10 cysts in each kidney, and with exclusion of other causes of extra renal or renal cyst formations using medical history, clinical examination and CT- and/ or MR-scanning. In addition, patients with a family history of ADPKD: $18-39$ yrs. with 3 cysts or more uni- or bilaterally/ $40-59$ yrs. with 2 or more cysts bilaterally/ $\geq 60$ yrs. with at least 4 cysts bilaterally [18]. Group 2: Same criteria as for Group 1, but without criteria for ADPKD. Group 3: Age 18 years or older. Healthy men and unfertile women or fertile women using safe contraception throughout the trial period (as indicated for Group 1). 


\section{Exclusion criteria}

Groups 1 and 2 Previous kidney transplantation. Previous kidney operation. Diabetes mellitus. Lithium nephropathy. Medullary cystic kidney disease. Neoplastic disease. Pregnancy or breastfeeding. Withdrawn consent. Intolerance to or unacceptable side effects to water deprivation test. Alcohol or drug abuse. Blood pressure > 170/110 mmHg despite treatment with metoprolol and/ or amlodipine. Group 3: Arterial hypertension i.e. office blood pressure above $140 \mathrm{mmHg}$ systolic and / or 90 $\mathrm{mmHg}$ diastolic. Significant clinical signs of heart disease, diseases of the lungs, liver, kidneys, endocrine organs, the brain or neoplastic disorders. Alcohol or drug abuse. Medical treatment except oral contraceptives. Smoking. Pregnancy or breastfeeding. Clinically significant abnormal findings in blood tests (plasma concentration of sodium, potassium, albumin, creatinine, bilirubin, alanine-amino-transaminase (ALAT), alkaline phosphatase, cholesterol, calcium, phosphate, parathyroid hormone (PTH), thyroid-stimulating hormone (TSH), blood concentration of hemoglobin, leukocytes, platelets and glycosylated hemoglobin A1c (HbA1c), or in the urine sample (leukocytes, nitrite, blood, glucose, albumin). Clinically significant changes in electrocardiogram. Blood donation within the last month before the test date in the first trial sequence. Intolerance to or unacceptable side effects to water deprivation test.

\section{Withdrawal criteria}

Development of exclusion criteria. Serious or unacceptable side effects.

\section{Effect variables}

The primary effect variable was u-osmolality (u-Osm) during thirst. The secondary effect variables were $p$ AVP, u-AQP-2, p-Osm, UO, $\mathrm{C}_{\mathrm{H} 20}$, fractional excretion of sodium $\left(\mathrm{FE}_{\mathrm{Na}}\right)$, u-ENaC, creatinine clearance $\left(\mathrm{C}_{\mathrm{Cre}}\right)$, brachial blood pressure (bBP), central blood pressure (cBP), PWV, AIx, PRC, p-AngII and p-Aldo.

\section{Number of subjects}

With a minimal relevant difference of $145 \mathrm{mOsm} / \mathrm{kg}$ in $\mathrm{u}$-Osm with an estimated standard deviation (SD) of $187 \mathrm{mOsm} / \mathrm{kg}, 16$ subjects were needed using a level of significance of $5 \%$ and a statistical power of $90 \%$. To counteract any dropouts, we included 20 participants from each group.

\section{Antihypertensive medications}

Antihypertensive medications including diuretics, angiotensinconverting enzyme inhibitors and angiotensin-II inhibitors were discontinued or substituted with metoprolol $25 \mathrm{mg}$ and/ or amlodipine $5 \mathrm{mg} 14$ days prior to each test day.
Throughout the study period, bBP was monitored using an oscillometric home blood pressure monitor. At a blood pressure of $>170 / 110 \mathrm{mmHg}$, metoprolol $25 \mathrm{mg}$ and/or amlodipine $5 \mathrm{mg}$ was given and increased up to metoprolol $100 \mathrm{mg}$ and / or amlodipine $10 \mathrm{mg}$. Subjects were discontinued from the study if blood pressure above $170 / 110 \mathrm{mmHg}$ continued despite treatment with metoprolol $100 \mathrm{mg}$ and/ or amlodipine $10 \mathrm{mg}$. Immediately after the examination day ended, the usual antihypertensive treatment was resumed.

\section{Ethics}

Regional Committee on Health Research Ethics approved the study (case number: 1-10-72-147-17). The study was done in agreement with the Declaration of Helsinki and was registered at clinicaltrials.gov (identifier: NCT04363554). Written informed consent was obtained from each subject.

\section{Experimental procedure}

The study took place at the Laboratory in the University Clinic in Nephrology and Hypertension. On the day prior to the examination day, all subjects consumed their habitual intake of food and beverage, but no alcohol until 07.30 PM. Thereafter, the subjects fasted and thirsted during $12 \mathrm{~h}$ before arriving at the Laboratory in the University Clinic in Nephrology and Hypertension. Measurements took place in a quiet and temperaturecontrolled room $\left(22-25^{\circ} \mathrm{C}\right)$, and the subjects were in a supine position. The central and brachial blood pressure was measured every $20 \mathrm{~min}$ by Mobil-O-Graph ${ }^{\circ} \mathrm{PWA}$ mounted on the upper arm. In the other arm an intravenous catheter was placed to collect blood samples. Urine samples were collected by voiding in standing or sitting position after blood samples had been collected. The subjects were weighed at arrival and every two hours during the examination. During the water deprivation test, urine was collected during $12 \mathrm{~h}$ from 0730 PM the day before arrival to the laboratory to 0730 $\mathrm{AM}$ on the examination day (Period 1). In addition, urine was collected in three periods: $0730 \mathrm{AM}$ to 0830 AM (Period 2), $0830 \mathrm{AM}$ to $1030 \mathrm{AM}$ (Period 3), and $1030 \mathrm{AM}$ to $1230 \mathrm{PM}$ (Period 4). Urine samples were taken for measurements of $\mathrm{u}-\mathrm{Osm}, \mathrm{u}-\mathrm{AQP}-2$ and $\mathrm{u}$ ENaC, u-Na, u-K, u-albumin (u-Alb), u-creatinine. Blood samples were drawn at the end of Periods 2, 3 and 4 for determination of $\mathrm{p}$-AVP, $\mathrm{p}$-Osm, PRC, $\mathrm{p}$-AngII, $\mathrm{p}$-Aldo, plasma creatinine, $\mathrm{p}-\mathrm{Na}, \mathrm{p}-\mathrm{K}$, and $\mathrm{p}$-alb.

\section{Measurements \\ Renal function}

The CKD-EPI formula was used to calculate estimated GFR (eGFR). Clearance (C) of substance $\mathrm{X}$ was calculated as $\left.C_{X}=U_{X} * U O / P_{X}\right)$, where $U O$ is urine excretion rate, $U_{X}$ denotes concentration of $x$ in urine, while $P_{X}$ 
denotes concentration of $\mathrm{x}$ in plasma. $\mathrm{FE}_{\mathrm{Na}}$ was calculated with the formula: $\mathrm{FE}_{\mathrm{Na}}=100 *((\mathrm{u}-\mathrm{Na} * \mathrm{p}-\mathrm{Cr})) /$ $((\mathrm{p}-\mathrm{Na} * \mathrm{u}-\mathrm{Cr}))$. Free water clearance was calculated with the formula: $\mathrm{C}_{\mathrm{H} 2 \mathrm{O}}=\mathrm{UO}-\mathrm{C}_{\mathrm{osm}}$.

\section{$A Q P 2$ and $E N a C$ in urine}

At $-20^{\circ} \mathrm{C}$, urine samples were kept frozen until assayed. As previously described, u-AQP2 was determined by radioimmunoassay (RIA) [19, 20]. Professor Soren Nielsen and Professor Robert Fenton (The Water and Salt Research Center, Aarhus University, Denmark) provided with rabbit antiAQP2 antibodies. The minimal detection level was $32 \mathrm{pg} /$ tube, inter-assay was $11.7 \%$ and the intra-assay $5.9 \%$. As described previously $\mathrm{u}$-ENaCY was measured by RIA [21, 22]. Lofstrand, Gaithersburg, Maryland, USA synthesized the $\mathrm{ENaC \gamma}$. Professor Soren Nielsen and Professor Robert Fenton (The Water and Salt Research Center, Aarhus University, Denmark) provided with the $\mathrm{ENaCY}$ antibody. Minimal detection level was $35 \mathrm{pg} /$ tube, inter-assay was $10 \%$ at a mean level of $338 \mathrm{pg} /$ tube, $9 \%$ at a mean level of $743 \mathrm{pg} /$ tube, and intra-assay was $5.0 \%$ in the range $125-135 \mathrm{pg} /$ tube and $5.6 \%$ in the range $290-380 \mathrm{pg} /$ tube.

\section{Vasoactive hormones in plasma}

We centrifuged the blood samples for measurements of vasoactive hormones, for $10 \mathrm{~min}$ at $2200 \mathrm{G}$ and $4^{\circ} \mathrm{C}$. The plasma was thereafter separated from blood cells and kept frozen until assayed. As previously described, pAngII and p-AVP were extracted from plasma with $\mathrm{C}_{18}$ Sep-Pak (Waters Corporation, Milford, MA, USA) and determined by RIA [23, 24]. Professor Jacques Dürr (Miami, FL, USA) provided with the antibodies against AVP. Minimal detection level was $0.5 \mathrm{pmol} / \mathrm{L}$, interassay was $13 \%$ and intra-assay was $9 \%$. From the Department of Clinical Physiology, Glostrup Hospital, Denmark antibodies against AngII were obtained. Minimal detection level was $2 \mathrm{pmol} / \mathrm{L}$, inter-assay was $12 \%$ and intraassay was $8 \%$. A RIA kit from Demeditec Diagnostics $\mathrm{GmbH}$ (Kiel, Germany) was used to determined p-Aldo. Minimal detection level was $14.8 \mathrm{pg} / \mathrm{mL}$, inter-assay was $10.2 \%$ and intra-assay was $11.9 \%$. A RIA kit from CIS Bio International (Gif-Sur-Yvette Cedex, France) was used to determined PRC. Minimal detection level was 1 $\mathrm{pg} / \mathrm{mL}$, inter-assay was $4.1 \%$ and intra-assay was $1.8 \%$.

\section{Other biochemical measurements}

$\mathrm{A}_{2} \mathrm{O}$ Advanced Automated Osmometer (Advanced Instruments, MA, USA) was used to measure u-Osm and p-Osm. Plasma concentration of sodium, potassium, albumin, hemoglobin, leukocytes, platelets, creatinine, bilirubin, ALAT, alkaline phosphatase, cholesterol, calcium, phosphate, $\mathrm{PTH}, \mathrm{TSH}$ and $\mathrm{HbA1c}$ were measured using routine methods at the Department of Clinical Biochemistry (Holstebro Hospital, Denmark).

\section{Brachial and central blood pressure}

$\mathrm{BP}$ was measured every twenty minutes throughout the examination day. Heart rate, bBP, cBP, mean arterial pressure (MAP), PWV and AIx was measured using an oscillometric device (Mobil-O-Graph ${ }^{\ominus}$ PWA).

\section{Statistics}

IBM SPSS statistics version 20 (SPSS Inc., Chicago, IL, USA) was used to perform statistical analyses. For comparison between and within the three groups, we used A General Linear Model with Greenhouse-Geisser correction for violating the assumption of sphericity with repeated-measures ANOVA. Data were tested for normal distribution. For comparison between two groups, we used a paired or unpaired t-test, when data showed normal distribution. For data which did not show normal distribution, we used Mann-Whitney' s U test for unpaired data, and Wilcoxon's Signed Rank Test for paired data. Statistical significance was set at $<0.05$ in all analyses. Data with normal distribution are reported as means \pm SD and data with non-normal distribution are reported as medians with 25 and $75 \%$ percentiles in brackets.

\section{Results}

\section{Demographics}

In Table 1, baseline demographics and clinical characteristics are presented. Twenty ADPKD patients with chronic kidney disease stages I-IV were allocated to the study. All ADPKD patients were included according to the classic Ravine criteria [18]. One patient was excluded due to cannulation problems. Two patients were excluded due to withdrawal of consent. Thus, 17 patients were included in Group 1. The distribution of these patients in different CKD stages is as follows: CKD stage 1 $(n=4)$, CKD stage $2(N=8)$, CKD stage $3 \mathrm{a}(n=3)$, CKD stage $3 \mathrm{~b}(n=1)$, CKD stage $4(\mathrm{n}=1)$. Twenty nonADPKD patients with CKD stage I-IV were allocated to the study. One patient was excluded due to side effects of the background antihypertensive medicine. Three patients were excluded due to withdrawal of consent. Thus, 16 patients were included in Group 2. The distribution of these patients in different CKD stages is as follows: CKD stage $1(n=4)$, CKD stage $2(N=4)$, CKD stage $3 \mathrm{a}(n=2)$, CKD stage $3 \mathrm{~b}(\mathrm{n}=2)$, CKD stage $4(\mathrm{n}=$ 4). Twenty healthy controls were included in the study. Two subjects were excluded due to withdrawal of consent. Thus, 18 subjects were included in Group 3.

$\mathrm{Al}$ three groups had similar age (ADPKD patients had a median age of 53 years, non-ADPKD patients 56 years, healthy controls 57 years, $p=0.557$ between ADPKD and non-ADPKD patients, $p=0.503$ between ADPKD patients and healthy controls and $p=0.878$ between nonADPKD patients and healthy controls). ADPKD patients and non-ADPKD patients had similar eGFR $(71 \pm 26 \mathrm{ml} /$ 
Table 1 Baseline demographics of the participants in the study. Patients with adult dominant polycystic kidney disease (ADPKD), patients with non-ADPKD kidney disease (Non-ADPKD), and healthy control subjects (Controls)

\begin{tabular}{llll}
\hline & ADPKD & Non-ADPKD & Controls \\
\hline Number of subjects $(\mathrm{n})$ & 17 & 16 & 18 \\
Age (years) & $53[44 ; 63]$ & $56[43 ; 71]$ & $57[54 ; 66]$ \\
Gender (men/women) & $8 / 9$ & $9 / 7$ & $8 / 10$ \\
Office systolic brachial BP (mmHg) & $138 \pm 16^{*}$ & $130 \pm 16$ & $125 \pm 10$ \\
Office diastolic brachial BP (mmHg) & $79 \pm 11 \#$ & $72 \pm 9$ & $74 \pm 7$ \\
eGFR (ml/min/1.73m $\left.{ }^{2}\right)$ & $71 \pm 26^{*}$ & $63 \pm 33^{*}$ & $87 \pm 13$ \\
P-Creatinine $(\mu \mathrm{mol} / \mathrm{l})$ & $101 \pm 38^{*}$ & $124 \pm 57^{*}$ & $76 \pm 11$ \\
U-Albumin $(\mathrm{mg} / \mathrm{l})$ & $14[8 ; 53]^{* \#}$ & $81[26 ; 283]^{*}$ & $8[3 ; 11]$ \\
\hline
\end{tabular}

Values represent $\mathrm{n}$ in either group or mean \pm SD or median with 25 and $75 \%$ percentiles in brackets. ${ }^{*}=p<0.05$ between ADPKD or non-ADPKD patients and healthy controls. $\#=p<0.05$ between ADPKD and non-ADPKD patients

$\mathrm{min} / 17.3 \mathrm{~m}^{2}$ and $\left.63 \pm 33 \mathrm{ml} / \mathrm{min} / 1.73 \mathrm{~m}^{2}, p=0.433\right)$, but both patient groups had a lower eGFR compare to healthy controls $\left(87 \pm 13 \mathrm{ml} / \mathrm{min} / 1.73 \mathrm{~m}^{2}, p=0.026\right.$ and $p=0.011$, respectively). ADPKD patients' antihypertensive treatment before this present study were: angiotensin II-receptor blockers $(n=7)$ ACE-inhibitors $(n=7)$, calcium-antagonists $(n=6)$, loop diuretics $(n=2)$, thiazides $(n=4)$, beta-adrenergic blockers $(n=4)$, alfablockers $(n=1)$ and potassium-sparing diuretics $(n=1)$. Non-ADPKD patients' antihypertensive treatment before this present study were: angiotensin II-receptor blockers $(n=5)$, ACE-inhibitors $(\mathrm{n}=4)$, calcium-antagonists $(\mathrm{n}=$ 4), loop diuretics $(n=2)$ and beta-adrenergic blockers $(n=3)$. Among ADPKD patients, 11 received metoprolol, 13 amlodipine, and 2 no antihypertensive treatment during the study period. Among non-ADPKD patients, 5 received metoprolol, 5 amlodipine, and 6 no antihypertensive treatment during the study period. Overall, more antihypertensive treatment was needed in the ADPKD group. In Group 1, 2 patients had a negative family story. In Group 2, 10 patients had a renal biopsy and 6 patients had no biopsy. The primary kidney disease was chronic non-specified glomerulonephritis in 5 patients, chronic interstitial nephritis in 2 patients, focal segmental glomerulosclerosis (FSGS) in 3 patients. The patients in Group 2 had a stable kidney function for more than 3 months and none received immunosuppressive therapy.

\section{Renal water excretion}

Table 2 shows $\mathrm{u}-\mathrm{Osm}, \mathrm{UO}, \mathrm{C}_{\mathrm{H} 2 \mathrm{O}}$, and $\mathrm{u}-\mathrm{AQP} 2$, and Table 4 shows p-Osm and p-AVP.

Comparisons between the three groups showed no significant differences in u-Osm during Period 1 (ADPKD patients: $498 \mathrm{mosmol} / \mathrm{kg}$, non-ADPKD patients: 496 mosmol $/ \mathrm{kg}$, healthy controls: $620 \mathrm{mosmol} / \mathrm{kg}, p=0.979$ between ADPKD and non-ADPKD patients, $p=0.074$ between ADPKD patients and healthy controls and $p=$ 0.122 between non-ADPKD patients and healthy controls). During Period 2, u-Osm was lower in both ADPK
D patients $(518 \mathrm{mosmol} / \mathrm{kg})$ and non-ADPKD patients (603 mosmol $/ \mathrm{kg}$ ) compared to healthy controls (765 mosmol $/ \mathrm{kg}$ ) with $p<0.001$ and $p=0.006$, respectively). These significant differences remained throughout Period 3 and $4(p<0.05)$.

There were no differences in UO between the three groups during Period $1(1.6 \mathrm{ml} / \mathrm{min}$ in ADPKD patients, $1.5 \mathrm{ml} / \mathrm{min}$ in non-ADPKD patients, and $1.1 \mathrm{ml} / \mathrm{min}$ in healthy controls, $p=0.832$ between ADPKD and nonADPKD patients, $p=0.052$ between ADPKD patients and healthy controls, and $p=0.057$ between non-ADPK $\mathrm{D}$ patients and healthy controls). During Period 2, ADPKD patients had an increased UO compare to healthy controls $(1.3 \mathrm{ml} / \mathrm{min}$ vs. $0.7 \mathrm{ml} / \mathrm{min} p<0.001)$, and this difference persisted during Periods 3 and $4(p<$ $0.05)$. During period 2, non-ADPKD patients had an increased UO compared to healthy controls during Period $2(1.0 \mathrm{ml} / \mathrm{min}$ vs. $0.7 \mathrm{ml} / \mathrm{min}, p=0.008)$, and this difference persisted in Period 3 and $4(\mathrm{p}<0.05)$. No differences were seen between ADPKD and non-ADPKD patients during any of the periods $(p=0.832$ in Period 1 , $p=0.119$ in Period 2, $p=0.557$ in Period 3 and $p=0.468$ in Period 4).

$\mathrm{C}_{\mathrm{H} 2 \mathrm{O}}$ did not differ between the groups $(p=0.482)$.

$\mathrm{U}-\mathrm{AQP} 2$ excretion rate was decreased in non-ADPKD patients compared to healthy controls during Period 1 $(0.4 \mathrm{ng} / \mathrm{min}$ vs. $0.7 \mathrm{ng} / \mathrm{min}, p=0.039)$. During Periods 2 , 3 and 4, both ADPKD and non-ADPKD patients had a decreased $\mathrm{u}-\mathrm{AQP} 2$ excretion rate compared to healthy controls $(p<0.05)$. No significant difference was measured between ADPKD and non-ADPKD patients during Periods 2, 3 and 4 ( $p=0.339$ in Period 2, $p=0.708$ in Period 3 and $p=0.708$ in Period 4).

P-osmolality and AVP did not deviate significantly between the three groups during period $2-4(p=0.236$ and $p=0.317$, respectively) (Table 4 ).

Comparison within each group showed no significant changes in $\mathrm{u}$-Osm, $\mathrm{UO}, \mathrm{C}_{\mathrm{H} 2 \mathrm{O}}, \mathrm{u}-\mathrm{AQP} 2, \mathrm{p}-\mathrm{Osm}$ and $\mathrm{p}$ AVP during the test $(>0.05)$. 
Table 2 U-osmolality (U-Osm), urine excretion of aquaporin2 (U-AQP2), urine output (UO), and free water clearance ( $\left.\mathrm{C}_{\mathrm{H} 2 \mathrm{O}}\right)$ during a water deprivation test in patients with adult dominant polycystic kidney disease (ADPKD), patients with non-ADPKD kidney disease (Non-ADPKD), and healthy control subjects (Controls). Urine was collected in four periods. Period 1 (twelve hours): from 0730 PM the day before arrival to the laboratory to $0730 \mathrm{AM}$ on the examination day. Period 2 (one hour): 0730 to 0830 AM. Period 3 (two hours): 0830-1030 AM. Period 4 (two hours): 1030-1230 AM

\begin{tabular}{|c|c|c|c|c|}
\hline & $\begin{array}{l}\text { Period } 1 \\
\text { 07.30 PM- 07.30 AM }\end{array}$ & $\begin{array}{l}\text { Period } 2 \\
07.30 \text { AM- } 08.30 \text { AM }\end{array}$ & $\begin{array}{l}\text { Period } 3 \\
08.30 \text { AM-10.30 AM }\end{array}$ & $\begin{array}{l}\text { Period } 4 \\
10.30 \text { AM- } 12.30 \text { PM }\end{array}$ \\
\hline \multicolumn{5}{|l|}{ U-Osm (mosmol/kg) } \\
\hline ADPKD & $498 \pm 149$ & $518 \pm 143^{*}$ & $491 \pm 133^{*}$ & $569 \pm 105^{*}$ \\
\hline Non-ADPKD & $496 \pm 220$ & $603 \pm 143^{*}$ & $532 \pm 192^{*}$ & $579 \pm 114^{*}$ \\
\hline Controls & $620 \pm 233$ & $765 \pm 150$ & $694 \pm 198$ & $757 \pm 167$ \\
\hline Comparison within groups & 0.339 & & & \\
\hline Comparison between groups & $<0.001$ & & & \\
\hline \multicolumn{5}{|l|}{ UO (ml/min) } \\
\hline ADPKD & $1.6 \pm 0.7$ & $1.3 \pm 0.5^{*}$ & $1.8 \pm 1.1^{*}$ & $1.3 \pm .5^{*}$ \\
\hline Non-ADPKD & $1.5 \pm 0.6$ & $1.0 \pm 0.3^{*}$ & $1.6 \pm 0.7^{*}$ & $1.2 \pm 0.4^{*}$ \\
\hline Controls & $1.1 \pm 0.6$ & $0.7 \pm 0.3$ & $1.0 \pm 0.5$ & $0.9 \pm 0.3$ \\
\hline Comparison within groups & 0.736 & & & \\
\hline Comparison between groups & 0.001 & & & \\
\hline \multicolumn{5}{|l|}{$\mathrm{C}_{\mathrm{H} 2 \mathrm{O}}(\mathrm{ml} / \mathrm{min})$} \\
\hline ADPKD & $-0.8 \pm 0.5$ & $-0.9 \pm 0.5$ & $-0.9 \pm 0.8$ & $-1.1 \pm 0.4$ \\
\hline Non-ADPKD & $-0.8 \pm 0.7$ & $-1.0 \pm 0.5$ & $-0.9 \pm 0.5$ & $-1.1 \pm 0.4$ \\
\hline Controls & $-0.9 \pm 0.5$ & $-1.1 \pm 0.5$ & $-1.1 \pm 0.4$ & $-1.3 \pm 0.3$ \\
\hline Comparison within groups & 0.560 & & & \\
\hline Comparison between groups & 0.482 & & & \\
\hline \multicolumn{5}{|l|}{ U-AQP2 (ng/ml) } \\
\hline ADPKD & $0.8 \pm 0.3$ & $0.9 \pm 0.4^{*}$ & $0.7 \pm 0.3^{*}$ & $0.8 \pm 0.2^{*}$ \\
\hline Non-ADPKD & $0.8 \pm 0.6$ & $1.0 \pm 0.5^{*}$ & $0.7 \pm 0.4$ & $0.8 \pm 0.2^{*}$ \\
\hline Controls & $1.1 \pm 0.5$ & $1.5 \pm 0.6$ & $1.1 \pm 0.7$ & $1.1 \pm 0.4$ \\
\hline Comparison within groups & 0.407 & & & \\
\hline Comparison between groups & 0.001 & & & \\
\hline \multicolumn{5}{|l|}{ AQP2 (ng/min) } \\
\hline ADPKD & $0.6[0.2 ; 0.8]$ & $0.7[0.4 ; 1.5]^{*}$ & $0.5[0.3 ; 0.9]^{*}$ & $0.6[0.3 ; 0.9]^{*}$ \\
\hline Non-ADPKD & $0.4[0.2 ; 0.6]^{*}$ & $1.0[0.6 ; 1.6]^{*}$ & $0.5[0.2 ; 1.0]^{*}$ & $0.7[0.5 ; 1.0]^{*}$ \\
\hline Controls & $0.7[0.2 ; 0.6]$ & $2.1[1.5 ; 3.8]$ & $1.5[1.1 ; 2.1]$ & $1.4[1.0 ; 2.2]$ \\
\hline Kruskal-Wallis test & 0.097 & 0.001 & 0.003 & 0.002 \\
\hline
\end{tabular}

A General Linear Model with Greenhouse-Geisser correction was used for comparison within and between the three groups. Values represent mean \pm SD or median with 25 and $75 \%$ percentiles in brackets $*=p<0.05$ between ADPKD or non-ADPKD- patients and healthy controls. \# $=p<0.05$ between ADPKD and non-ADPKD- patients

\section{Weight loss and total urine output}

Weight loss was similar in the groups during the examination day $(2.4 \pm 1.0 \mathrm{~kg}$ in ADPKD patients, $2.2 \pm 1.4 \mathrm{~kg}$ in non-ADPKD patients and $2.2 \pm 0.9 \mathrm{~kg}$ in healthy controls, $p=0.634$ between ADPKD and non-ADPKD patients, $p=0.394$ between ADPKD patients and healthy controls and $p=0.860$ between non-ADPKD patients and healthy controls). However, ADPKD and non-ADPK $\mathrm{D}$ patients had a higher urine output during the whole examination compared to healthy controls $(1551 \pm 485$ $\mathrm{ml}$ in ADPKD patients, $1475 \pm 480 \mathrm{ml}$ in non-ADPKD patients and $1114 \pm 445 \mathrm{ml}$ in healthy controls, $p=0.654$ between ADPKD and non-ADPKD patients, $p=0.009$ between ADPKD patients and controls, $p=0.030$ between non-ADPKD patients and controls).

\section{Renal sodium excretion}

Table 3 shows $\mathrm{FE}_{\mathrm{Na}}$ and $\mathrm{u}-\mathrm{ENaC}$.

Comparisons between groups showed that $\mathrm{FE}_{\mathrm{Na}}$ was significantly higher in both ADPKD patients (1.1, 0.9, 
Table 3 Fractional excretion of sodium, ( $\mathrm{FE}_{\mathrm{Na}}$ ), urine excretion of a fraction of epithelial sodium channel (u-ENaC), urine albumin excretion rate $(u-A l b)$, creatinine clearance $\left(C_{\text {Creatinine }}\right)$ during a water deprivation test in patients with adult dominant polycystic kidney disease (ADPKD), patients with non-ADPKD kidney disease (Non-ADPKD), and healthy control subjects (Controls). Urine was collected in four periods. Period 1 (twelve hours): from 0730 PM the day before arrival to the laboratory to $0730 \mathrm{AM}$ on the examination day. Period 2 (one hour): 0730 to 0830 AM. Period 3 (two hours): 0830-1030 AM. Period 4 (two hours): 1030-1230 AM

\begin{tabular}{|c|c|c|c|c|}
\hline & $\begin{array}{l}\text { Period } 1 \\
\text { 07.30 PM- 07.30 AM }\end{array}$ & $\begin{array}{l}\text { Period } 2 \\
07.30 \text { AM- } 08.30 \text { AM }\end{array}$ & $\begin{array}{l}\text { Period } 3 \\
08.30 \text { AM-10.30 AM }\end{array}$ & $\begin{array}{l}\text { Period } 4 \\
10.30 \text { AM- } 12.30 \text { PM }\end{array}$ \\
\hline \multicolumn{5}{|l|}{$\mathrm{FE}_{\mathrm{Na}}(\%)$} \\
\hline ADPKD & $1.1 \pm 0.5^{*}$ & $0.9 \pm 0.5^{*}$ & $1.2 \pm 0.7^{*}$ & $1.2 \pm 0.7^{*}$ \\
\hline Non-ADPKD & $1.3 \pm 0.8^{*}$ & $1.1 \pm 0.7^{*}$ & $1.5 \pm 1.0^{*}$ & $1.4 \pm 1.0^{*}$ \\
\hline Controls & $0.6 \pm 0.3$ & $0.5 \pm 0.2$ & $0.7 \pm 0.3$ & $0.8 \pm 0.3$ \\
\hline Comparison within groups & 0.910 & & & \\
\hline Comparison between groups & 0.014 & & & \\
\hline \multicolumn{5}{|l|}{ U-ENaC (ng/ml) } \\
\hline ADPKD & $0.6 \pm 0.3^{*}$ & $0.6 \pm 0.3^{*}$ & $0.4 \pm 0.2^{*}$ & $0.4 \pm 0.2^{*}$ \\
\hline Non-ADPKD & $0.6 \pm 0.3$ & $0.9 \pm 0.5$ & $0.5 \pm 0.3^{*}$ & $0.5 \pm 0.2^{*}$ \\
\hline Controls & $0.9 \pm 0.4$ & $1.2 \pm 0.5$ & $0.8 \pm 0.5$ & $0.8 \pm 0.3$ \\
\hline Comparison within groups & 0.394 & & & \\
\hline Comparison between groups & 0.003 & & & \\
\hline \multicolumn{5}{|l|}{ U-ENaC (ng/min) } \\
\hline ADPKD & $0.3[0.1 ; 0.9]^{*}$ & $0.5[0.2 ; 1.0]^{*}$ & $0.3[0.2 ; 0.6]^{*}$ & $0.3[0.2 ; 0.5]^{*}$ \\
\hline Non-ADPKD & $0.3[0.2 ; 0.6]^{*}$ & $0.9[0.5 ; 1.2]^{*}$ & $0.3[0.1 ; 0.6]^{*}$ & $0.4[0.3 ; 1.0]^{*}$ \\
\hline Controls & $0.8[0.4 ; 2.0]$ & $1.7[1.2 ; 2.9]$ & $1.2[0.5 ; 2.1]$ & $0.9[0.7 ; 1.9]$ \\
\hline Krusal-Wallis H & 0.023 & 0.001 & 0.011 & $<0.001$ \\
\hline \multicolumn{5}{|l|}{ U-Alb (mg/min) } \\
\hline ADPKD & $0.01[0.01 ; 0.02]^{*}$ & $0.02[0.01 ; 0.05] \#$ & $0.01[0.00 ; 0.03]$ & $0.01[0.01 ; 0.03] \#$ \\
\hline Non-ADPKD & $0.04[0.01 ; 0.17]^{*}$ & $0.08[0.02 ; 0.44]^{*}$ & $0.02[0.01 ; 0.49]^{*}$ & $0.4[0.14 ; 0.22]^{*}$ \\
\hline Controls & $0.01[0.00 ; 0.01]$ & $0.01[0.01 ; 0.02)$ & $0.01[000 ; 0.02]$ & $0.01[0.00 ; 0.02]$ \\
\hline Kruskal-Wallis test & 0.003 & 0.001 & 0.032 & 0.001 \\
\hline \multicolumn{5}{|l|}{$\mathrm{C}_{\text {Creatinine }}(\mathrm{ml} / \mathrm{min})$} \\
\hline ADPKD & $104.0 \pm 43.3$ & $109 \pm 41$ & $108 \pm 36^{*}$ & $106 \pm 40^{*}$ \\
\hline Non-ADPKD & $101.3 \pm 57.9$ & $93 \pm 50^{*}$ & $101 \pm 50^{*}$ & $94 \pm 48^{*}$ \\
\hline Controls & $127.7 \pm 27.7$ & $133 \pm 28$ & $131 \pm 24$ & $132 \pm 23$ \\
\hline Comparison within groups & 0.809 & & & \\
\hline Comparison between groups & 0.040 & & & \\
\hline
\end{tabular}

A General Linear Model with Greenhouse-Geisser correction was used for comparison within and between the three groups. Values represent mean \pm SD or median with 25 and $75 \%$ percentiles in brackets $*=p<0.05$ between ADPKD or non-ADPKD- patients and healthy controls. \# $=p<0.05$ between ADPKD and non-ADPKD- patients

1.2 , and $1.2 \%$, Periods $1-4$, respectively) and non-ADPKD patients $(1.3,1.1,1.5$, and $1.4 \%$, Periods $1-4$, respectively) compare to healthy controls $(0.6,0.5,0.7$, and $0.8 \%, \mathrm{Pe}-$ riods $1-4$, respectively) throughout the examination day $(p<0.05)$. No difference was seen between ADPKD and non-ADPKD- patients $(p=0.394$ in Period $1, p=0.328$ in Period 2, $p=0.372$ in Period 3 and $p=0.527$ in Period 4).

$\mathrm{U}-\mathrm{ENaC}$ excretion rates were similar in ADPKD patients $(0.3 \mathrm{ng} / \mathrm{min}, 0.5 \mathrm{ng} / \mathrm{min}, 0.3 \mathrm{ng} / \mathrm{min}$, and $0.3 \mathrm{ng} / \mathrm{min}$, Periods $1-4$, respectively) and non-ADPKD patients $(0.3$ ng/min, $0.9 \mathrm{ng} / \mathrm{min}, 0.3 \mathrm{ng} / \mathrm{min}$, and $0.4 \mathrm{ng} / \mathrm{min}$, Periods $1-4$, respectively, $p>0.05)$. The level was significantly lower in both groups of patients compared to healthy controls in all the periods $(0.8 \mathrm{ng} / \mathrm{min}, 1.7 \mathrm{ng} / \mathrm{min}, 1.2 \mathrm{ng} / \mathrm{min}$, and $0.9 \mathrm{ng} / \mathrm{min}$, Periods $1-4$, respectively, $p<0.05)$.

Comparison within each group showed no significant changes in $\mathrm{FE}_{\mathrm{Na}}$ and $\mathrm{u}$-ENaC during the test.

Renal albumin excretion and creatinine clearance Table 3 shows u-Alb and creatinine clearance. 
During all Periods non-ADPKD patients had an increased albumin excretion rate compare to healthy controls $(p=0.002$ in Period 1, $p<0.001$ in Period 2, $p=$ 0.014 in Period 3 and $\mathrm{p}<0.001$ in Period 4).

Furthermore, non-ADPKD patients had an increased albumin excretion rate in Period 2 and Period 4 compared to ADPKD patients $(p=0.008$ and $p=0.013$, respectively). Creatinine clearance was lower in both patient groups compared to healthy controls $(p<0.05)$. Creatinine clearance was the same between ADPKD patients and non-ADPKD patients throughout the examination day ( $p=0.882$ in Period $1, p=0.333$ in Period 2, $p=0.622$ in Period 3 and $p=0.450$ in Period 4).

\section{Vasoactive hormones}

Table 4 shows vasoactive hormones in plasma.

PRC was lower in ADPKD patients compared to nonADPKD patients throughout the examination day $(p=$ 0.021 in Period 2, $p=0.027$ in Period 3 and $p=0.031$ in Period 4). There was no difference between healthy controls and ADPKD or non-ADPKD patients $(p>0.05)$. PAldo was higher in ADPKD and non-ADPKD patients compared to healthy controls throughout the examination day $(p<0.05)$. There was no difference between ADPKD and non-ADPKD patients $(p=0.221$ in Period 2, $p=0.171$ in Period 3 and $p=0.121$ in Period 4). PAngII did not change during the examination day ( $p=$ 0.348 ), and there were similar p-AngII-levels in the three groups $(p=0.715)$.

\section{Systemic haemodynamics}

Table 5 shows systolic bBP, diastolic bBP, mean blood pressure, heart rate, systolic $\mathrm{cBP}$, diastolic $\mathrm{cBP}$, AIx and PWV.

Systolic bBP were higher in ADPKD and non-ADPKD patients compared to healthy controls $(p<0.05)$. Systolic bBP was also increased in ADPKD patients compare to non-ADPKD patients, except during Period 4 ( $p=0.009$ in Period 1, $p=0.015$ in Period 2, $p=0.005$ in Period 3 and $p=0.057$ in Period 4). Systolic cBP showed the same pattern regarding to ADPKD patients in comparison to non-ADPKD patients and healthy controls. However, non-ADPKD patients only had increased systolic cBP compared to healthy controls during Period $1(p=$ 0.038). Mean BP, diastolic bBP and diastolic cBP were increased in ADPKD patients compare to non-ADPKD patients and healthy controls throughout the examination day $(p<0.05)$.

Heart rate was slightly increased in both group of patients compared with the controls $(\mathrm{p}<0.05)$.

AIx and PWV did not change during the examination day ( $p=0.645$ and $p=0.124$,respectively) and there were similar AIx and PWV in the three groups $(p=0.903$ and $p=0.819$, respectively).

\section{Discussion}

The present paper reports urine concentration ability, tubular function, vasoactive hormones and systemic hemodynamics in ADPKD patients compared to patients with similar degree of impairment in renal function (non-ADPKD patients), and healthy controls during seventeen hours of water deprivation.

The main findings were that urine concentration ability was reduced to the same extent in patients with ADPKD and non-ADPKD chronic kidney diseases with the same level of renal function compared to healthy controls. In addition, the lower urine excretion rates of $\mathrm{AQP} 2$ and $\mathrm{ENaC}$ suggest that the underlying mechanism may be a reduced tubular response to vasopressin and aldosterone.

\section{Renal water excretion}

During the first $12 \mathrm{~h}$ of the concentration test (Period 1 ), we did not measure any significant difference in $\mathrm{u}-\mathrm{Osm}$, $\mathrm{UO}, \mathrm{C}_{\mathrm{H} 2 \mathrm{O}}$ and AQP2 excretion rate between the 3 groups. During the following $5 \mathrm{~h}$ (Periods $2-4$ ), u-Osm, $\mathrm{UO}$ and $\mathrm{AQP}$ excretion rate were the same in ADPKD and non-ADPKD, but significantly lower than in controls, except for UO, which was increased compared to healthy controls. Apparently, a plateau in $\mathrm{u}$-Osm was reached in Period 2 without further significant changes during the following periods. The maximum $\mathrm{u}$-Osm in the healthy controls was around $760 \mathrm{mosmol} / \mathrm{kg}$. This is lower than expected in younger healthy subjects, but urine concentrating ability decreases with age, and our control group of healthy subjects had an average age of 57 years, which explains the $\mathrm{u}$-Osm level in the control group. Vasopressin is responsible for the final regulation of renal water excretion, which occurs in the distal part of the nephron. Vasopressin is released by increased osmotic activity in plasma, and the hormone stimulates opening of the aquaporin2 water channels in the principal cells in the distal part of the nephron via a cascade of intracellular reactions. This facilitates water absorption. Aquaporin 2 is excreted in the urine as extracellular vesicles, and AQP2 is localized predominantly to urinary exosomes with preserved water channel activity [25]. The amount of AQP2 in exosomes released from the collecting duct cells is physiologically regulated, and exosomal AQP2 closely reflects cellular expression [26]. When urine is stored in a deep freezer, the membranes of the extracellular vesicles are disrupted, which allow AQP2 antibodies to bind to their epitopes located inside the extracellular vesicles [27]. Our measurement of $\mathrm{u}$ AQP2 reflects the activity of the transport via the aquaporin water channels. The results showed that urine concentration ability was impaired in both groups of patients with kidney diseases. In addition, the lower level of AQP2 excretion rate demonstrated a tubular defect or 
Table 4 Plasma concentrations of vasopressin ( $p$-AVP), renin (PRC), aldosterone (p-Aldo), angiotensin II (p-Angll), and plasma osmolality ( $\mathrm{p}-\mathrm{Osm}$ ) during a water deprivation test in patients with adult dominant polycystic kidney disease (ADPKD), patients with non-ADPKD kidney disease (Non-ADPKD), and healthy control subjects (Controls). Urine was collected in four periods. Period 1 (twelve hours): from 0730 PM the day before arrival to the laboratory to 0730 AM on the examination day. Period 2 (one hour): 0730 to 0830 AM. Period 3 (two hours): 0830-1030 AM. Period 4 (two hours): 1030-1230 AM. Blood samples were taken at the end of periods 2, 3 and 4

\begin{tabular}{|c|c|c|c|}
\hline & $\begin{array}{l}\text { End of Period } 2 \\
08.30 \text { AM }\end{array}$ & $\begin{array}{l}\text { End of Period } 3 \\
10.30 \mathrm{AM}\end{array}$ & $\begin{array}{l}\text { End of Period } 4 \\
12.30 \mathrm{AM}\end{array}$ \\
\hline \multicolumn{4}{|l|}{ P-AVP (pg/ml) } \\
\hline ADPKD & $0.5 \pm 0.4$ & $0.6 \pm 0.4$ & $0.6 \pm 0.4$ \\
\hline Non-ADPKD & $0.6 \pm 0.4$ & $0.6 \pm 0.3$ & $0.6 \pm 0.3$ \\
\hline Controls & $0.4 \pm 0.3$ & $0.4 \pm 0.3$ & $0.5 \pm 0.3$ \\
\hline Comparison within groups & 0.753 & & \\
\hline Comparison between groups & 0.317 & & \\
\hline \multicolumn{4}{|l|}{ PRC (pg/ml) } \\
\hline ADPKD & $7.4[4.3 ; 8.8] \#$ & $5.4[4.1 ; 8.6] \#$ & $6.0[3.6 ; 8.7] \#$ \\
\hline Non-ADPKD & $12.9[5.8 ; 26.4]$ & $11.4[4.9 ; 26.4]$ & $10.6[4.8 ; 24.8]$ \\
\hline Controls & $7.1[5.9 ; 10.4]$ & $7.4[4.7 ; 9.7]$ & $6.4[4.8 ; 8.7]$ \\
\hline Kruskal-Wallis test & 0.050 & 0.054 & 0.079 \\
\hline \multicolumn{4}{|l|}{ P-Angll (pg/ml) } \\
\hline ADPKD & $5.5 \pm 4.0$ & $5.0 \pm 3.1$ & $5.7 \pm 3.5$ \\
\hline Non-ADPKD & $6.6 \pm 3.6$ & $6.1 \pm 2.7$ & $6.2 \pm 3.2$ \\
\hline Controls & $5.7 \pm 2.4$ & $6.0 \pm 3.3$ & $5.4 \pm 3.0$ \\
\hline Comparison within groups & 0.348 & & \\
\hline Comparison between groups & 0.715 & & \\
\hline \multicolumn{4}{|l|}{ P-Aldo (pmol/l) } \\
\hline ADPKD & $324[203 ; 478]^{*}$ & $305[218 ; 484]^{*}$ & $273[222 ; 385]^{*}$ \\
\hline Non-ADPKD & $257[201 ; 314]^{*}$ & $230[179 ; 380]^{*}$ & $213[172 ; 334]^{*}$ \\
\hline Controls & $145[126 ; 223]$ & $120[99 ; 157]$ & $101[95 ; 154]$ \\
\hline Kruskal-Wallis test & $<0.001$ & $<0.001$ & $<0.001$ \\
\hline \multicolumn{4}{|l|}{ P-Osm (mosmol/kg) } \\
\hline ADPKD & $294 \pm 4$ & $293 \pm 4$ & $293 \pm 4$ \\
\hline Non-ADPKD & $296 \pm 8$ & $296 \pm 8$ & $295 \pm 7$ \\
\hline Controls & $293 \pm 4$ & $293 \pm 4$ & $292 \pm 4$ \\
\hline Comparison within groups & 0.651 & & \\
\hline Comparison between groups & 0.236 & & \\
\hline
\end{tabular}

A General Linear Model with Greenhouse-Geisser correction was used for comparison within and between the three groups. Values represent mean \pm SD or median with 25 and $75 \%$ percentiles in brackets ${ }^{*}=\mathrm{p}<0.05$ between ADPKD or non-ADPKD- patients and healthy controls. \# $=p<0.05$ between ADPKD and non-ADPKD- patients

a reduced tubular responsiveness in patients, which is in accordance with an earlier study [9]. We could not falsify the 0-hypothesis that ADPKD patients have same urine concentrating capacity as patients with other types of chronic kidney diseases. - at least at a level of GFR around $60-70 \mathrm{ml} / \mathrm{min}$. In good agreement with the present study, Meijer et al. measured a decreased maximal $\mathrm{u}$-Osm in ADPKD compared to healthy controls after intramuscular injection of desmopressin [15]. Contrary to our study, Zittema et al. measured decreased maximal u-Osm in patients with ADPKD compared with IgA-nephropathy after desmopressin injection. This suggested a different concentration ability depending on primary kidney disease [17]. In a previous study, we measured similar u-Osm in chronic kidney disease, when ADPKD was excluded. Most likely, the discrepancies in results between the studies can be attributed to differences in eGFR, in test conditions such as duration of the test and degree of water deprivation, methods used, i.e. thirst or desmopressin injection, and primary 
Table 5 Hemodynamics during a water deprivation test in patients with adult dominant polycystic kidney disease (ADPKD), patients with non-ADPKD kidney disease (Non-ADPKD), and healthy control subjects (Controls)

\begin{tabular}{|c|c|c|c|c|}
\hline & 08.30 AM-09-30 AM & 09.30 AM-10.30 AM & 10.30 AM-11.30 AM & $11.30 \mathrm{AM}-12$ \\
\hline \multicolumn{5}{|l|}{ Systolic bBP (mm Hg) } \\
\hline ADPKD & $129 \pm 9 * \#$ & $131 \pm 9 * \#$ & $133 \pm 11^{*} \#$ & $131 \pm 12^{*}$ \\
\hline Non-ADPKD & $122 \pm 14^{*}$ & $124 \pm 16^{*}$ & $125 \pm 16^{*}$ & $126 \pm 18^{*}$ \\
\hline Controls & $113 \pm 12$ & $117 \pm 12$ & $118 \pm 14$ & $120 \pm 16$ \\
\hline Comparison within groups & 0.282 & & & \\
\hline Comparison between groups & 0.004 & & & \\
\hline \multicolumn{5}{|l|}{ Diastolic bBP (mm Hg) } \\
\hline ADPKD & $83 \pm 9 * \#$ & $84 \pm 9^{*} \#$ & $84 \pm 9^{*} \#$ & $84 \pm 10^{*} \#$ \\
\hline Non-ADPKD & $77 \pm 9$ & $76 \pm 10$ & $77 \pm 11$ & $77 \pm 11$ \\
\hline Controls & $74 \pm 9$ & $74 \pm 10$ & $76 \pm 11$ & $76 \pm 11$ \\
\hline Comparison within groups & 0.394 & & & \\
\hline Comparison between groups & $<0.001$ & & & \\
\hline \multicolumn{5}{|l|}{ MAP (mm Hg) } \\
\hline ADPKD & $104 \pm 8^{*} \#$ & $106 \pm 9 * \#$ & $107 \pm 9 * \#$ & $106 \pm 10^{*} \#$ \\
\hline Non-ADPKD & $98 \pm 11^{*}$ & $98 \pm 12$ & $99 \pm 13$ & $100 \pm 14$ \\
\hline Controls & $92 \pm 10$ & $94 \pm 11$ & $95 \pm 12$ & $96 \pm 13$ \\
\hline Comparison within groups & 0.268 & & & \\
\hline Comparison between groups & $<0.001$ & & & \\
\hline \multicolumn{5}{|l|}{ HR (beats/ min) } \\
\hline ADPKD & $60 \pm 10^{*}$ & $62 \pm 11^{*}$ & $62 \pm 11^{*}$ & $64 \pm 11^{*}$ \\
\hline Non-ADPKD & $59 \pm 8$ & $60 \pm 7^{*}$ & $61 \pm 8^{*}$ & $62 \pm 8^{*}$ \\
\hline Controls & $57 \pm 6$ & $57 \pm 6$ & $58 \pm 7$ & $59 \pm 7$ \\
\hline Comparison within groups & 0.250 & & & \\
\hline Comparison between groups & 0.029 & & & \\
\hline \multicolumn{5}{|l|}{ Systolic CBP (mmHg) } \\
\hline ADPKD & $119 \pm 11^{*} \#$ & $122 \pm 11^{*} \#$ & $123 \pm 13^{*} \#$ & $122 \pm 14^{*}$ \\
\hline Non-ADPKD & $112 \pm 14^{*}$ & $114 \pm 15$ & $115 \pm 15$ & $117 \pm 17$ \\
\hline Controls & $106 \pm 12$ & $110 \pm 13$ & $111 \pm 13$ & $113 \pm 15$ \\
\hline Comparison within groups & 0.195 & & & \\
\hline Comparison between groups & $<0.001$ & & & \\
\hline \multicolumn{5}{|l|}{ Diastolic cBP (mm Hg) } \\
\hline ADPKD & $84 \pm 9^{*} \#$ & $85 \pm 9^{*} \#$ & $86 \pm 9 * \#$ & $85 \pm 10^{*} \#$ \\
\hline Non-ADPKD & $78 \pm 10$ & $76 \pm 10$ & $78 \pm 11$ & $78 \pm 12$ \\
\hline Controls & $74 \pm 10$ & $75 \pm 11$ & $76 \pm 10$ & $76 \pm 11$ \\
\hline Comparison within groups & 0.710 & & & \\
\hline Comparison between groups & $<0.001$ & & & \\
\hline \multicolumn{5}{|l|}{ Alx (\%) } \\
\hline ADPKD & $31 \pm 13$ & $28 \pm 13$ & $31 \pm 13$ & $28 \pm 13$ \\
\hline Non-ADPKD & $31 \pm 16$ & $31 \pm 16$ & $29 \pm 17$ & $29 \pm 15$ \\
\hline Controls & $31 \pm 12$ & $32 \pm 14$ & $29 \pm 13$ & $28 \pm 14$ \\
\hline Comparison within groups & 0.645 & & & \\
\hline Comparison between groups & 0.903 & & & \\
\hline
\end{tabular}

$\operatorname{PW}(\mathrm{m} / \mathrm{s})$ 
Table 5 Hemodynamics during a water deprivation test in patients with adult dominant polycystic kidney disease (ADPKD), patients with non-ADPKD kidney disease (Non-ADPKD), and healthy control subjects (Controls) (Continued)

\begin{tabular}{|c|c|c|c|c|}
\hline & 08.30 AM-09-30 AM & 09.30 AM-10.30 AM & 10.30 AM-11.30 AM & 11.30 AM-12.30 PM \\
\hline ADPKD & $8 \pm 2$ & $8 \pm 2$ & $8 \pm 2$ & $8 \pm 2$ \\
\hline Non-ADPKD & $8 \pm 2$ & $8 \pm 2$ & $8 \pm 2$ & $8 \pm 2$ \\
\hline Controls & $8 \pm 2$ & $8 \pm 2$ & $8 \pm 2$ & $8 \pm 2$ \\
\hline Comparison within groups & 0.124 & & & \\
\hline Comparison between groups & 0.819 & & & \\
\hline
\end{tabular}

A General Linear Model with Greenhouse-Geisser correction was used for comparison within and between the three groups. Values represent mean \pm SD or median with 25 and $75 \%$ percentiles in brackets ${ }^{*}=p<0.05$ between ADPKD or non-ADPKD patients and healthy controls. \# $=p<0.05$ between ADPKD and non-ADPKD patients

kidney disease. Overall, patients with kidney disease and moderate to severe reduction in renal function have a decrease in urine concentration ability. This abnormality can be attributed to reduced tubular capacity to decrease water excretion, which in the present study is documented by the lower AQP2 excretion rate than in healthy controls.

During water deprivation, body weight decreased to the same extent in all three groups around 2.2 to $2.4 \mathrm{~kg}$ on average, which documented that the patients and controls had thirsted. However, p-AVP, p-Osm and $\mathrm{C}_{\mathrm{H} 2 \mathrm{O}}$ did not change significantly during water deprivation and did not differ between the groups. Increased or unchanged levels of p-AVP, p-Osm and $\mathrm{C}_{\mathrm{H} 2 \mathrm{O}}$ have previously been reported during urine concentration tests depending on the degree of renal impairment in patients studied $[8,9,16,17]$. In our study, patients had not severely impaired renal function, which can explain the lack of deviation from the control group regarding these variables. In addition, a prolonged water deprivation test might have demasked differences between the two groups of patients.

The activity in the osmoregulatory system can be measured by $\mathrm{p}$-AVP, but plasma levels of copeptin have also been used in recent years. Pre-pro-AVP is proteolytically cleaved into vasopressin, neurophysin II and copeptin, and the three substances are stored in secretory granules in the posterior pituitary. They are released on osmotic and non-osmotic stimuli and copeptin and vasopressin are released in equimolar amounts into the circulation. Thus, copeptin can be used as a surrogate vasopressin marker. Since copeptin is more stable in plasma than vasopressin, some researchers have used copeptin to evaluate the activity in the osmoregulatory system. However, when blood samples for vasopressin measurement are drawn, prepared and plasma stored under well-defined conditions, p-AVP correctly reflects the activity in the osmoregulatory system both during normal physiological conditions and during disturbances in fluid balance [28-30] .

\section{Renal sodium excretion}

Zittema et al. measured an increase in $\mathrm{u}-\mathrm{Na}$ in ADPKD patients during a water deprivation test, but there was no change in IgA patients [17]. In the present study, $\mathrm{FE}_{\mathrm{Na}}$ was the same throughout the examination day in ADPKD and non-ADPKD patients, but $\mathrm{FE}_{\mathrm{Na}}$ was increased compared to healthy controls as expected. We measured a lower $\mathrm{ENaC}$ excretion rate in both $\mathrm{ADPKD}$, and non-ADPKD patients compare to healthy controls during urine concentration test. This suggests a defect in tubular function with a reduced response to aldosterone, which was increased in both groups of patients compared to the control group. It is in good agreement with previous experimental studies of collecting duct principal cells in mice [31].

\section{Renal function}

Clearance of creatinine was the same during the consecutive periods of the urine concentration test in the two groups of patients and the healthy controls. However, albumin excretion rate was higher in the non-ADPKD patients during the test than in ADPKD and controls. This could indicate a lower tubular albumin absorption in nonADPKD, which presumably reflects different types of tubular lesion among the two groups of patients. Another explanation could be a more severe glomeruli injury in the non-ADPKD patients compare to ADPKD patients. These results are in agreement with the findings of Zittema et al., who measured an increase in u-Alb in IgA patients but no change in ADPKD patients [17].

\section{Vasoactive hormones}

In the present paper, we measured a higher level of $\mathrm{p}$ Aldo in both ADPKD and non-ADPKD compared to healthy controls, which is in agreement with other studies [32, 33]. The renin-angiotensin-aldosterone system regulates blood pressure and renal sodium excretion via angiotensin's vasoconstrictor effect on the vascular bed, and via aldosterone stimulation of sodium absorption in the distal part of the nephron. The effect of aldosterone is mediated by an effect on the epithelial sodium channels. Our measurement of $\mathrm{u}-\mathrm{ENaC}$ reflects the activity of the transport via these channels. As aldosterone regulates $\mathrm{ENaC}$ using the mineralocorticoid receptor in the principal cells, it could be expected that $\mathrm{u}-\mathrm{ENaC}$ also 
was higher in the two groups of patients. However, u$\mathrm{ENaC}$ was lower in patients than controls. The most likely explanation is a lack of tubular responsiveness to aldosterone caused by the primary kidney disease. The enhanced PRC in non-ADPKD patients compared to ADPKD patients and healthy controls is in accordance with a previous study [34].

\section{Systemic hemodynamics}

During the water deprivation test, ADPKD patients had a slightly higher systolic and diastolic bBP and cBP compare to non-ADPKD patients and healthy controls. This was in spite of the fact that more patients in the ADPK $\mathrm{D}$ group received more antihypertensive therapy. However, we do not think that these small difference in blood pressure level could explain any differences in effects variables in the present study.

\section{Strengths and limitations}

The match regarding age, gender and renal function is a strength in our study as well as the uniform procedure of the concentration test, and its' length. Patients received antihypertensive treatment during the study because we did not find it ethically justified to discontinue antihypertensive medication. It was standardized to only metoprolol and/or amlodipine, and a possible influence on the results is estimated to be absent or minimal during the concentration test. We did not measure blood pressure at the start of the water deprivation test, but it was controlled regularly during the weeks before the patients were studied, and many times during the last four periods of water deprivation. It is a weakness of the study that the first part of the water deprivation test took place at home and not in hospital. Thus, a fluid intake could not completely be excluded. However, the weight loss documented the patients had thirsted. The wide range of impaired kidney functions, from CKD I-IV may also be a limitation to the interpretation of the results. It can be speculated, whether a significant difference in other effect variables might be detected between the two groups of patients, if the groups have been larger, but we calculated the size of the groups based on the best available information.

\section{Conclusion}

Urine concentration ability was reduced to the same extent in patients with ADPKD and other chronic kidney diseases with the same level of renal impairment compared to healthy controls. In addition, the lower urine excretion of $\mathrm{AQP} 2$ and $\mathrm{ENaC}$ suggest that the underlying mechanism may be reduced tubular response to vasopressin and aldosterone. We could not falsify the 0hypothesis that ADPKD patients have same urine concentrating capacity as patients with other types of chronic kidney diseases.

\section{Abbreviations}

ALAT: alanine-amino-transaminase; Alx: augmentation index; ADPK

D: Autosomal dominant polycystic kidney disease; AQP2: aquaporin-2; bBP: brachial blood pressure; $C B P$ : central blood pressure; $C_{C r}$ : creatinine clearance; $\mathrm{C}_{\mathrm{H} 2 \mathrm{O}}$ : free water clearance; $\mathrm{CKD}$ : chronic kidney disease; eGFR: estimated glomerular filtration rate; ENaC: epithelial sodium channel; $\mathrm{FE}_{\mathrm{Na}}$ : fractional excretion of sodium; HbA1c: glycosylated hemoglobin A1c; Non-ADPKD: patients with chronic kidney disease except ADPKD; MAP: mean arterial pressure; $\mathrm{P}$ : $p$-value; $\mathrm{p}$-Aldo: plasma aldosterone; $\mathrm{p}$-Angll: plasma angiotensin; p-AVP: plasma vasopressin; P-Osm: plasma osmolality; PRC: plasma renin concentration; PTH: parathyroid hormone; PWV: pulse wave velocity; TSH: thyroid-stimulating hormone; UO: urine output; UOsm: urinary osmolality

\section{Acknowledgements}

We thank laboratory technicians, Anne Mette Ravn, Henriette Vorup Simonsen and Kirsten Nygaard, for their skillful assistance.

\section{Authors' contributions}

All authors have contributed to the publication. MHM, EBP and JNB designed the project. MHM performed the experiments. MHM and FHM performed laboratory analysis. MHM performed statistical analysis. MHM, FHM, EBP and JNB wrote and edited the manuscript. All authors have read and approved the manuscript.

Funding

No funding was obtained for this study.

\section{Availability of data and materials}

The protocol and datasets used and/or analysed during the current study are available from the corresponding author on reasonable request.

\section{Ethics approval and consent to participate}

Regional Committee on Health Research Ethics approved the study (case number: 1-10-72-147-17). The study was done in agreement with the Declaration of Helsinki and was registered at clinicaltrials.gov (identifier: NCT04363554). Written informed consent was obtained from each subject.

\section{Consent for publication}

Not applicable.

\section{Competing interests}

The authors declare that they have no competing interests.

Received: 12 May 2020 Accepted: 23 August 2020

Published online: 31 August 2020

\section{References}

1. Nielsen S, Kwon TH, Christensen BM, Promeneur D, Frokiaer J, Marples D. Physiology and pathophysiology of renal aquaporins. J Am Soc Nephrol. 1999;10(3):647-63.

2. Kwon TH, Nielsen J, Knepper MA, Frokiaer J, Nielsen S. Angiotensin II AT1 receptor blockade decreases vasopressin-induced water reabsorption and AQP2 levels in NaCl-restricted rats. Am J Physiol Renal Physiol. 2005;288(4): F673-84.

3. Lee YJ, Song IK, Jang KJ, Nielsen J, Frokiaer J, Nielsen S, Kwon TH. Increased AQP2 targeting in primary cultured IMCD cells in response to angiotensin II through AT1 receptor. Am J Physiol Renal Physiol. 2007;292(1):F340-50.

4. Wong NL, Tsui JK. Angiotensin II upregulates the expression of vasopressin V2 mRNA in the inner medullary collecting duct of the rat. Metabolism. 2003:52(3):290-5.

5. Wang W, Li C, Nejsum LN, Li H, Kim SW, Kwon TH, Jonassen TE, Knepper MA, Thomsen K, Frokiaer J, Nielsen S. Biphasic effects of ANP infusion in conscious, euvolumic rats: roles of AQP2 and ENaC trafficking. Am J Physiol Renal Physiol. 2006;290(2):F530-41.

6. de Seigneux S, Nielsen J, Olesen ET, Dimke H, Kwon TH, Frokiaer J, Nielsen S. Long-term aldosterone treatment induces decreased apical but increased basolateral expression of AQP2 in CCD of rat kidney. Am J Physiol Renal Physiol. 2007;293(1):F87-99. 
7. Lee J, Yoo K, Kim SW, Jung KH, Ma SK, Lee YK, Kim WY, Kim J, Choi KC Decreased expression of aquaporin water channels in denervated rat kidney. Nephron Physiol. 2006;103(4):p170-8.

8. Argent NB, Burrell LM, Goodship TH, Wilkinson R, Baylis PH. Osmoregulation of thirst and vasopressin release in severe chronic renal failure. Kidney Int. 1991;39(2):295-300.

9. Pedersen EB, Thomsen IM, Lauridsen TG: Abnormal function of the vasopressin-cyclic-AMP-aquaporin2 axis during urine concentrating and diluting in patients with reduced renal function. A case control study. BMC Nephrol 2010, 11:26-2369-11-26.

10. Torres VE, Harris PC, Pirson Y. Autosomal dominant polycystic kidney disease. Lancet. 2007;369(9569):1287-301.

11. Schrier RW, Brosnahan G, Cadnapaphornchai MA, Chonchol M, Friend K, Gitomer B, Rossetti S. Predictors of autosomal dominant polycystic kidney disease progression. J Am Soc Nephrol. 2014;25(11):2399-418.

12. Nakajima A, Lu Y, Kawano H, Horie S, Muto S. Association of arginine vasopressin surrogate marker urinary copeptin with severity of autosomal dominant polycystic kidney disease (ADPKD). Clin Exp Nephrol. 2015;19(6):1199-205.

13. Wang $X$, Wu Y, Ward CJ, Harris PC, Torres VE. Vasopressin directly regulates cyst growth in polycystic kidney disease. J Am Soc Nephrol. 2008;19(1):102-8.

14. Yamaguchi T, Pelling JC, Ramaswamy NT, Eppler JW, Wallace DP, Nagao S, Rome LA, Sullivan LP, Grantham JJ. CAMP stimulates the in vitro proliferation of renal cyst epithelial cells by activating the extracellular signal-regulated kinase pathway. Kidney Int. 2000;57(4):1460-71

15. Meijer E, Rook M, Tent H, Navis G, van der Jagt EJ, de Jong PE, Gansevoort RT. Early renal abnormalities in autosomal dominant polycystic kidney disease. Clin J Am Soc Nephrol. 2010;5(6):1091-8.

16. Zittema D, Boertien WE, van Beek AP, Dullaart RP, Franssen CF, de Jong PE, Meijer E, Gansevoort RT. Vasopressin, copeptin, and renal concentrating capacity in patients with autosomal dominant polycystic kidney disease without renal impairment. Clin J Am Soc Nephrol. 2012;7(6):906-13.

17. Zittema D, Casteleijn NF, Bakker SJ, Boesten LS, Duit AA, Franssen CF, Gaillard CA, Gansevoort RT. Urine concentrating capacity, vasopressin and Copeptin in ADPKD and IgA nephropathy patients with renal impairment. PLoS One. 2017;12(1):e0169263.

18. Ravine D, Gibson RN, Walker RG, Sheffield LJ, Kincaid-Smith P, Danks DM. Evaluation of ultrasonographic diagnostic criteria for autosomal dominant polycystic kidney disease 1. Lancet. 1994;343(8901):824-7.

19. Pedersen RS, Bentzen $H$, Bech JN, Pedersen EB. Effect of water deprivation and hypertonic saline infusion on urinary AQP2 excretion in healthy humans. Am J Physiol Renal Physiol. 2001;280(5):F860-7.

20. Graffe CC, Bech JN, Pedersen EB. Effect of high and low sodium intake on urinary aquaporin-2 excretion in healthy humans. Am J Physiol Renal Physiol. 2012;302:F264-75.

21. Matthesen SK, Larsen T, Lauridsen TG, Vase H, Gjorup PH, Nykjaer KM, et al. Effect of amiloride and spironolactone on renal tubular function, ambulatory blood pressure, and pulse wave velocity in healthy participants in a double-blinded, randomized, placebo-controlled, crossover trial. Clin Exp Hypertens. 2012;34:588-600.

22. Al Therwani S, Malmberg MES, Rosenbaek JB, Bech JN, Pedersen EB. Effect oftolvaptan on renal handling of water and sodium, GFR and central hemodynamics in autosomal dominant polycystic kidney disease during inhibition of the nitricoxide system: a randomized, placebo-controlled, double blind, crossover study. BMC Nephrol. 2017 Aug 15;18(1):268.

23. Pedersen EB, Danielsen $H$, Spencer ES. Effect of indapamide on renal plasma flow, glomerular filtration rate and arginine vasopressin in plasma in essential hypertension. Eur J Clin Pharmacol. 1984;26:543-7.

24. Pedersen EB, Eiskjaer H, Madsen B, Danielsen H, Egeblad M, Nielsen CB. Effect of captopril on renal extraction of renin, angiotensin II, atrial natriuretic peptide and vasopressin, and renal vein renin ratio in patients with arterial hypertension and unilateral renal artery disease. Nephrol Dial Transplant. 1993:8:1064-70.

25. Miyazawa Y, Mikami S, Yamamoto K, Sakai M, Saito T, Yamamoto T, Ishibashi K, Sasaki S. AQP2 in human urine is predominantly localized to exosomes with preserved water channel activities. Clin Exp Nephrol. 2018;22:782-8.

26. Street JM, Birkhoff W, Menzies RI, Webb DJ, Bailey MA, Dear JW. Exosomal transmission of functional aquaporin 2 in kidney cortical collecting duct cells. J Physiol. 2011;589:6119-27.

27. Nameta M, Saijo Y, Ohmoto Y, Katsuragi K, Yamamoto K, Yamamoto T, Ishibashi K, Sasaki S. Disruption of membranes of extracellular vesicles is necessary for ELISA determination of urine AQP2: proof of disruption and epitopes of AQP2 antibodies. Int J Mol Sci. 2016;17(10):1634.
28. Pedersen EB, Lamm LU, Albertsen K, Madsen M, Bruun-Petersen G, Henningsen K, Friedrich U, Magnusson K. Familial cranial diabetes insipidus: a report of five families. Genetic, diagnostic and therapeutic aspects. Q J Med. 1985;57:883-96.

29. Rittig S, Knudsen UB, Norgaard JP, Pedersen EB, Djurhuus JC. Abnormal diurnal rhythm of plasma vasopressin and urinary output in patients with enuresis. Am J Phys. 1989;256:F664-71.

30. Rittig S, Robertson GL, Siggaard C, Kovacs L, Gregersen N, Nyborg J, Pedersen EB. Identification of 13 new mutations in the vasopressinneurophysin II gene in 17 kindreds with familial autosomal dominant neurohypophyseal diabetes insipidus. Am J Hum Genet. 1996;58:107-17.

31. Veizis El, Carlin CR, Cotton CU. Decreased amiloride-sensitive Na absorption in collecting duct principal cells isolated from BPK ARPKD mice. Am J Physiol Renal Physiol. 2004;286:F244-54.

32. Berl T, Katz FH, Henrich WL, de Torrente A, Schrier RW. Role of aldosterone in the control of sodium excretion in patients with advanced chronic renal failure. Kidney Int. 1978;14(3):228-35.

33. Hene RJ, Boer P, Koomans HA, Mees EJ. Plasma aldosterone concentrations in chronic renal disease. Kidney Int. 1982;21(1):98-101.

34. Hamrahian SM, Falkner B. Hypertension in chronic kidney disease. Adv Exp Med Biol. 2017;956:307-25.

\section{Publisher's Note}

Springer Nature remains neutral with regard to jurisdictional claims in published maps and institutional affiliations.

\section{Ready to submit your research? Choose BMC and benefit from:}

- fast, convenient online submission

- thorough peer review by experienced researchers in your field

- rapid publication on acceptance

- support for research data, including large and complex data types

- gold Open Access which fosters wider collaboration and increased citations

- maximum visibility for your research: over $100 \mathrm{M}$ website views per year

At BMC, research is always in progress.

Learn more biomedcentral.com/submissions 